\title{
The phenotype, psychotype and genotype of bruxism
}

\author{
NORMA CRUZ-FIERRO ${ }^{1}$, MARGARITA MARTÍNEZ-FIERRO ${ }^{2}$, RICARDO M. CERDA-FLORES ${ }^{3}$, \\ MAYRA A. GÓMEZ-GOVEA ${ }^{4}$, IVÁN DELGADO-ENCISO ${ }^{5}$, LAURA E. MARTÍNEZ-DE-VILLARREAL ${ }^{6}$, \\ MÓNICA T. GONZÁLEZ-RAMÍREZ ${ }^{1}$ and IRÁM PABLO RODRÍGUEZ-SÁNCHEZ ${ }^{6}$ \\ ${ }^{1}$ Universidad Autónoma de Nuevo León, Facultad de Psicología, Monterrey, Nuevo León 64460; \\ ${ }^{2}$ Molecular Medicine Laboratory, Unidad Académica de Medicina Humana y Ciencias de la Salud, La Escondida, \\ Zacatecas 98160; ${ }^{3}$ Universidad Autónoma de Nuevo León, Facultad de Enfermería, Monterrey, Nuevo León 64460; \\ ${ }^{4}$ Universidad Autónoma de Nuevo León, Facultad de Ciencias Biológicas, Ciudad Universitaria, San Nicolás de los Garza, \\ Nuevo León 66451; ${ }^{5}$ Instituto Estatal de Cáncer, Secretaria de Salud de Colima, La Esperanza, Colima 28085; \\ ${ }^{6}$ Universidad Autónoma de Nuevo León, Facultad de Medicina, Departamento de Genética, \\ Monterrey, Nuevo León 64460, México
}

Received January 5, 2017; Accepted January 11, 2018

DOI: 10.3892/br.2018.1041

\begin{abstract}
Bruxism is a jaw muscle activity that involves physio-pathological, psycho-social, hereditary and genetic factors. The purpose of this study was to determine the associations between self-reported bruxism, anxiety, and neuroticism personality trait with the rs6313 polymorphism in the gene HTR2A. A sample of 171 subjects of both sexes (14-53 years of age) was included. The control group (group 1 , $\mathrm{n}=60$ ) exhibited no signs or symptoms of bruxism. The case group had signs and symptoms of bruxism $(\mathrm{n}=112)$ and was subdivided into group 2, bruxism during sleep $(\mathrm{n}=22)$; group 3 , awake bruxism $(\mathrm{n}=44)$; and group 4 combined bruxism $(n=46)$. As diagnostic tools, the Self-Reported Bruxism Questionnaire (SBQ), the Beck Anxiety Inventory (BAI) and the Eysenck Personality Questionnaire Revised-Abbreviated (EPQR-A) were used. HTR2A (rs6313) SNPs were determined by qPCR for all the participants. The packages SPSS, maxLik and EPI-INFO were used for data analysis. The combined bruxism group reported higher scores in bruxism symptoms, mean $=32.21$; anxiety symptoms, mean $=14.80$; and neuroticism, mean $=3.26$. Combined bruxism was associated with a higher degree of neuroticism $(\mathrm{OR}=15.0$; CI 1.52-148.32) and anxiety in grade 3-moderate (OR=3.56; CI 1.27-10.03), and grade 4-severe (OR=8.40; CI 1.45-48.61), as determined using EPISODE computer software. Genotypic homogeneity analysis revealed no significant differences in allele frequency $(\mathrm{P}=0.612)$ among the four groups. The population was in
\end{abstract}

Correspondence to: Dr Irám Pablo Rodríguez-Sánchez, Universidad Autónoma de Nuevo León, Facultad de Medicina, Departamento de Genética, Av. Madero s/n Monterrey, Monterrey, Nuevo León 64460, México

E-mail: iramrodriguez@gmail.com

Key words: bruxism, anxiety, neuroticism, polymorphism
Hardy-Weinberg equilibrium (maxLik package). In conclusion, the three instruments confirm traits of bruxism, anxiety and neuroticism in individuals with bruxism. These data were ratified when the sample was divided by genotypic homogeneity. On the other hand, there was no significant difference between the groups in the SNPs rs6313 from the HTR2A gene.

\section{Introduction}

Bruxism is a repetitive muscular activity of the jaw characterized by grinding or clenching the teeth and by pulling or pushing the jaw. This can occur during sleep, 'sleep bruxism', or when awake, 'awake bruxism' (1). Development of this negative mechanical-physiological condition does not discriminate age, sex or ethnicity (2-5).

Worldwide epidemiological data of bruxism reported a prevalence of sleep bruxism of $15.9 \%$, and of awake bruxism of $23.8 \%(6,7)$. In Turkey, a prevalence of sleep bruxism of $14.1 \%$, of awake bruxism of $28.2 \%$, and of combined bruxism of $38.8 \%$, was reported (8). Other authors have reported a prevalence in adults of awake bruxism between 22.1 and $31 \%$, and of $12.8 \%$ of sleep bruxism (3). Etiologic factors, including physical, biological, psychological and pathological factors are involved $(6,8)$, albeit there is controversy regarding the influence of hereditary factors. A study in children reported a higher prevalence of bruxism (51.3\%) whenever one of the parents reported a history of sleep bruxism, in contrast to children of parents with no history (30.6\%) (9). Similarly, Michalowicz et al evaluated 494 monozygotic and dizygotic twins, and through questionnaires and clinical analysis they estimated the presence of signs and symptoms of bruxism (10). In their results, no significant differences in clenching or grinding the teeth were found, whether the twins had grown together or were separated. On the other hand, a case-control association study of 114 people in Japan, 48 as a control group and 66 presenting with a diagnosis of sleep bruxism made by using a portable electromyographic device, included the analysis of different variables such as temperament, 
character, and personality traits as well as related habits, and in parallel they genotyped 13 polymorphisms in four genes related to serotoninergic neurotransmission (SLC6A4, HTR 1A, HTR 2A and HTR2C). Their results established five predictors of sleep bruxism. These variables were analyzed using multivariate logistic regression stepwise analysis and the researchers reported that only carriers of the $\mathrm{C}$ allele of the SNP rs6313 $(102 \mathrm{C}>\mathrm{T})$ of the HTR2A gene were significantly associated with an increased risk of sleep bruxism $(\mathrm{OR}=4.250,95 \%$ CI $1.599-11.297 ; \mathrm{P}=0.004)$. Authors of that study also concluded that a genetic factor may contribute to the etiology of sleep bruxism (11). In addition, the HTR2A gene has been associated with other psychological and systemic conditions, including schizophrenia (12), obsessive compulsive disorders (13), and depressive disorders as well as with psychosomatic symptoms (14). It was also found, in the literature, that $5 H T 2 A$ is known as the $5-H T 2$ gene. In other studies, the interaction of serotonin (5-HT) as a neurotransmitter in behavioral responses to environmental stimuli particularly in the social environment has been reported, with this playing an important role in social responses and being associated with mood, sleep, circadian rhythm, thermoregulation, and social behavior. An association to the stress response and coping has also been reported $(15,16)$.

Several psychological traits that have been reported in individuals with bruxism, such as anxiety and neuroticism personality trait, suggesting an anxious individual, have been linked to the rs6313 polymorphism of the $5 H T 2 A$ gene $(17,18)$. In Mexico, the Sistema Nacional de Salud (National Health System) in 2009 reported a prevalence of bruxism of $4.6 \%$ in a sample of 10,536 users of public health services; however, these data did not include information from the private sector (19). It is important to study bruxism because it is an unfavorable condition for individuals who suffer from it. Furthermore, in previous studies, discrepancies in the results have been reported. In addition, other studies of this condition (bruxism) do not develop an integral analysis. Thus, research related to bruxism is focused on its etiology, epidemiology, pathophysiology, and alterations in sleep physiology $(6,20,21)$, and its relation with different psychological factors $(2,8,22,23)$. Different articles include an assessment of factor inheritance (9) because of the relationship between the function of a particular gene and its expression through physical and behavioral traits (24). Regarding the rs6313 polymorphism in the HTR $2 A$ gene, it has been associated with stress, and anxiety, because of the changes these emotions have in the serotonergic system (15-18), as well as with sleep bruxism (11).

Owing to the integrated relationship between these variables, the aim of the present study was to investigate the associations between self-reported bruxism, anxiety, and neuroticism personality trait with the rs6313 polymorphism in the gene $H T R 2 A$, in a population from Northeastern Mexico.

\section{Materials and methods}

Experimental design and origin of bio-specimens. A quantitative,descriptive,non-experimental,cross-sectional,multi-center association study was conducted in Northeastern Mexico. The selection of participants was based on the recommendations of the Temporomandibular Disorder (TMD)-RDC guidelines (25). Sample collection was performed for 3 months with a response rate of $87 \%$. A non-probability sample was used. Due to the lack of accurate data on the prevalence of bruxism in this population, the sample size was estimated from an infinite population. The control group consisted of 21 men, and 38 women with a mean age of 32.62 years (range, 14-53 years). The case group was comprised of 31 men and 81 women with a mean age of 33.45 years. The variables were assessed according to their cut-off points, determined by the authors of the different scores.

Dental evaluation. This was determined in three ways: i) Clinical diagnosis in order to identify and confirm the presence of signs and symptoms of bruxism; ii) an evaluation of self-reported signs and symptoms through the 'self-report of bruxism' questionnaire (26); and iii) the data provided by the subjects confirmed by an interview conducted by a dentist. For self-reported bruxism, the cut-off points were: $\mathrm{M}=11.0$ to 18.0 , unlikely bruxism symptoms; 19.0 to 24.0 , probable bruxism symptoms; and 25.0 to 40.0 , definitive bruxism symptoms. An adequate $\kappa$ coefficient was achieved in the correlation between the clinical diagnosis and recognition of oral signs and symptoms.

Psychological instruments. The presence of signs and symptoms of anxiety was evaluated by the Beck Anxiety Inventory (BAI), which was adapted for the Mexican population (27). To assess traits of neuroticism, the abbreviated personality traits questionnaire EPQR - adapted to Spanish was used (28). Both were carried out following the instructions of the authors. For the anxiety scale, the cut-off points were slight, $0-5$; minimum, 6-15; moderate, 16-30; and severe, 31-63. For neuroticism, a comparison of means was performed.

Genotyping. Genomic DNA was isolated from a sample of peripheral blood with EDTA using the QIAcube and the QIAamp ${ }^{\circledR}$ DNA Investigator kit and performed according to the manufacturer's instructions (Qiagen, Hilden, Germany). Genomic DNA was treated with RNase I (Invitrogen, Carlsbad, CA, USA) for $30 \mathrm{~min}$ at $37^{\circ} \mathrm{C}$ to remove traces of RNA. DNA quality and integrity were assessed by standard spectrophotometric and electrophoretic methods, respectively (NanoDrop Technologies, Wilmington, DE, USA). The rs6313 alleles from gene HTR2A (11) were determined by TaqMan ${ }^{\circledR}$ Assays-on-Demand, and TaqMan ${ }^{\circledR}$ Genotyping Master Mix, the procedures were carried out in Real-Time PCR system (Applied Biosystems, Foster City, CA, USA) (29).

Statistical analysis. The descriptive statistical analysis of values and the comparison of the level of perception of bruxism, symptoms of anxiety, and neuroticism personality traits, in individuals with waking bruxism, sleep bruxism, and without bruxism was performed using IBM SPSS (version 22; IBM Corp., Armonk, NY, USA). The EPI-INFO package was used to evaluate the odds ratio (OR) for anxiety and neuroticism. Genotype data analysis was performed using the maxLik (maximum likelihood) statistical program to differentiate the allele frequencies $\mathrm{C}$ and $\mathrm{T}$. In addition to the allelic discrimination, the Hardy-Weinberg equilibrium by 
Table I. Mean values and standard deviation for self-reported symptoms of bruxism, symptoms of anxiety, and personality trait of neuroticism for case and control group.

\begin{tabular}{llrrr}
\hline Items & Groups & $\mathrm{n}$ & Mean & SD \\
\hline Self-report of bruxism & G1 & 60 & 13.92 & 2.97 \\
& G2 & 22 & 24.64 & 6.35 \\
& G3 & 44 & 23.36 & 5.24 \\
& G4 & 46 & 32.21 & 7.5 \\
& Total & 172 & 22.60 & 9.04 \\
Anxiety symptoms & G1 & 60 & 8.38 & 8.27 \\
& G2 & 22 & 9.41 & 7.36 \\
& G3 & 44 & 11.50 & 10.34 \\
& G4 & 46 & 14.80 & 10.31 \\
Neuroticism trait & Total & 172 & 11.03 & 9.58 \\
& G1 & 60 & 2.28 & 1.49 \\
& G2 & 22 & 3 & 1.66 \\
& G3 & 44 & 2.27 & 1.83 \\
& G4 & 46 & 3.26 & 1.49 \\
& Total & 172 & 2.63 & 1.65 \\
\hline
\end{tabular}

SD, standard deviation.

exact text was determined, and allele association analysis was conducted.

\section{Results}

Mean values. A total of 171 subjects (control, $\mathrm{n}=59$; and cases, $\mathrm{n}=112$ ) were subdivided into groups that included individuals with self-reported symptoms of sleep bruxism $(n=22)$, awake bruxism $(n=46)$ and combined $(n=45)$, and a control group that reported no signs or related symptoms $(n=58)$. In this study, Cronbach's alpha of the Self-Reported Bruxism Questionnaire (SBQ) was $\alpha=0.869$. The highest score was reported by combined bruxism, mean $=32.21$ (Table I). A one-way ANOVA was performed to determine the significant differences among the test groups $(\mathrm{P} \leq 0.05)$ (Table II). The reliability of the psychometric scales BAI was $\alpha=0.908$. The mean of anxiety symptoms in the control group was 8.38 and of bruxism, 12.44. The correlation between anxiety levels and self-reported symptoms of bruxism was $\mathrm{r}=0.393(\mathrm{P}=0.01)$. The reliability of the EPQ-a was $\alpha=0.654$. The descriptive statistical analysis of neuroticism in $\mathrm{C} 1$ was mean $=2.28$, and the highest score reported in the subgroups was group 4 , mean $=3.26$ (Table I). The correlation between the levels of neuroticism and self-reported symptoms of bruxism was $\mathrm{r}=0.337(\mathrm{P}=0.01)$.

Hardy-Weinberg equilibrium and EPI-INFO software package. According to the maxLik statistical program, the four groups were in Hardy-Weinberg equilibrium. In the analysis of genotypic frequency $3 \times 4$, the following genotype frequency was observed in the control group $(\mathrm{G} 1, \mathrm{n}=60), \mathrm{C} / \mathrm{C}=8, \mathrm{~T} / \mathrm{T}=22$, $\mathrm{T} / \mathrm{C}=30$; in the subgroups with bruxism symptoms during sleep $(\mathrm{G} 2, \mathrm{n}=22), \mathrm{C} / \mathrm{C}=5, \mathrm{~T} / \mathrm{T}=8, \mathrm{~T} / \mathrm{C}=9$; while awake $(\mathrm{G} 3, \mathrm{n}=44)$, $\mathrm{C} / \mathrm{C}=4, \mathrm{~T} / \mathrm{T}=19 ; \mathrm{T} / \mathrm{C}=21 ;$ combined $(\mathrm{G} 4, \mathrm{n}=46), \mathrm{C} / \mathrm{C}=9, \mathrm{~T} / \mathrm{T}=18$,
Table II. One-way ANOVA between independent groups.

\begin{tabular}{lrr}
\hline & F & P-value \\
\hline Self-reported bruxism & 97.87 & 0.000 \\
Anxiety symptoms & 4.39 & 0.005 \\
Neuroticism trait & 4.38 & 0.005 \\
\hline
\end{tabular}

Table III. Genetic homogeneity analysis 3x4 (1 locus, 2 alleles: 1 and 2).

\begin{tabular}{llcccc}
\hline & \multicolumn{5}{c}{ Alleles } \\
\cline { 3 - 5 } Groups & $\chi^{2} \mathrm{HW}$ & 1 & 2 & SD & P-value \\
\hline G1 control & 0.051 & 0.3621 & 0.6379 & 1 & 0.82 \\
G2 case & 0.153 & 0.4545 & 0.5454 & 1 & 0.70 \\
G3 case & 0.152 & 0.3152 & 0.6848 & 1 & 0.70 \\
G4 case & 2.673 & 0.3778 & 0.6222 & 1 & 0.10 \\
Total & 0.51 & 0.3424 & 0.6576 & 1 & 0.82 \\
\hline
\end{tabular}

HW, Hardy-Weinberg; SD, standard deviation.

Table IV. EPI-INFO was used to assess the risk factor of neuroticism.

\begin{tabular}{lcccc}
\hline Strata & Control & Case & OR (1 ref.) & Woolf 95\% CI \\
\hline 0 & 6 & 1 & 1.00 & Reference \\
1 & 13 & 6 & 2.77 & $(0.25-30.54)$ \\
2 & 21 & 9 & 2.57 & $(0.26-25.90)$ \\
3 & 7 & 7 & 6.00 & $(0.57-63.68)$ \\
4 & 8 & 12 & 9.00 & $(0.94-86.53)$ \\
$5-6$ & 4 & 10 & 15.0 & $(1.52-148.32)$ \\
\hline
\end{tabular}

$\mathrm{T} / \mathrm{C}=19$. In this analysis no differences were found $(\mathrm{F}=4.517$, $\mathrm{P}=0.612$ ). In these results, we can identify that out of the four groups, the one that had the farthest $\mathrm{P}$-value from significance was the control group $(\mathrm{P}=0.82)$, unlike the combined bruxism group $(\mathrm{P}=0.10)$. For this reason, this group of combined bruxism was used to establish the risk factor of anxiety and neuroticism. The EPI-INFO software package was used and showed a higher risk factor of neuroticism (six levels, 0-5) at level 5 (maximum score) (OR=15.0; CI 1.52-148.32) (Table IV).

\section{Discussion}

The pathophysiological traits associated with bruxism were quantitatively measured by the SBQ (26). When the results obtained with the cutoffs established by the authors were compared, the mean of the bruxism group, 27.25 [standard deviation ( $\mathrm{SD})=7.66$, placed it in the range of the definitive clinical diagnosis of bruxism. In the data reported from the subgroups, the mean was higher in G4 than in the combined bruxism group, $32.21(\mathrm{SD}=7.50)$. In contrast to $\mathrm{G} 1$, the control 
group, $13.91(\mathrm{SD}=2.97)$ reflected a very low probability of symptoms associated with bruxism. With the results of this scale, we can confirm that those individuals who report combined bruxism perceive more symptoms associated with bruxism during wakefulness and during sleep, in contrast to those of the other subgroups.

The psychological traits evaluated were anxiety and neuroticism, as these, besides being associated with bruxism, have been associated with the 5HT2A (rs6313) SNPs. To measure anxiety symptoms, the BAI version adapted to the Mexican population was used (27). Regarding symptoms of anxiety in the control group, mean $=8.38(\mathrm{SD}=8.27)$, and bruxism, mean $=12.44(\mathrm{SD}=9.96)$ from the subgroups, the highest score was reported by the combined bruxism, mean $=14.80(\mathrm{SD}=10.30)$. These results confirm that the more the symptoms of bruxism, the higher the level of anxiety. The correlation between symptoms of anxiety and self-reported bruxism was $\mathrm{r}=0.393, \mathrm{P}=0.01$. Personality trait neuroticism was assessed with the Eysenck Personality Questionnaire Revised-abbreviated (EPQR-A), using the adapted Spanish version (28). The results for neuroticism in the control group were mean $=2.28(\mathrm{SD}=1.49)$, and for bruxism, mean $=2.82$ $(\mathrm{SD}=1.71)$. For the subgroups, the highest score was in the combined bruxism group, mean $=3.26(1.49)$. Bilateral correlation between levels of neuroticism and self-reported symptoms of bruxism was $\mathrm{r}=0.337(\mathrm{P}=0.01)$ and between neuroticism-anxiety, $\mathrm{r}=0.528(\mathrm{P}=0.01)$. The neuroticism trait indicates a tendency of the individual to present anxiety. These results indicate a greater tendency for neuroticism trait in individuals with more symptoms of self-reported bruxism and anxiety. The inherited context is controversial because some studies on families report a significant association when several members clench or grind their teeth as in the study performed by Lobbezoo et al (9). That study included 39 children aged 3 years and through a questionnaire they established whether any family members clenched or grinded their teeth. Their results reported a $51.3 \%$ higher prevalence of bruxism when one of the parents reported a history of sleep bruxism, in contrast to those children of parents with no history (30.6\%). Regarding research on twins, the study performed by Michalowicz et al (10), who evaluated 494 pairs of twins between 16 and 80 years $(M=46.4 \pm 12.3)$, identified no significant difference in grinding or clenching teeth in either types of monozygotic and dizygotic twins. Rintakoski et al, included 1,141 pairs of twins between 23 and 27 years of age $(M=24)(30)$. The diagnosis of bruxism was performed asking the question 'Do you grind your teeth?', giving five response options: Nightly, weekly, occasionally, or once a week, never, and I do not know; in order to classify patients according to their frequency of symptoms, 'weekly bruxism', 'rarely bruxes' and 'never bruxes'. Their results indicated that the genetic factor determines $52 \%$ of the variance for bruxism during sleep in both sexes.

Furthermore, research suggesting a genetic association is scarce, as in the case-control study of Abe et al (11), which investigated the association of genetic, psychological, and behavioral factors with sleep bruxism in a Japanese population. It included 114 individuals between 20 and 70 years of both sexes; 66 diagnosed with sleep bruxism and 48 as controls. It was through questionnaires adapted in Japanese, such as the
Epworth Sleepiness Scale (ESS), that it was possible to assess the presence or absence of snoring, apnea/hipopnea, and restless legs. By using the NEO-FFI questionnaire, personality traits were assessed together with the Temperament and Character Inventory (TCI). Those authors also included a questionnaire to assess the presence of familial aggregation with stressful events in the past, the habit of grinding during daytime, TMD and daytime headache, with the option of a dichotomous (yes/no) answer. As well as the presence of daily habits such as the amount of cigarettes smoked, alcohol ingestion, and caffeine intake, their results reported that only the presence of restless legs was associated with sleep bruxism $(\mathrm{P}=0.036)$. Regarding genotype, they found a significant association of the $\mathrm{C}$ allele carrier of the SNP rs6313 $(102 \mathrm{C}>\mathrm{T})$ from gene HTR2A with an increased risk of sleep bruxism $(\mathrm{OR}=4.250 ; 95 \%$ CI 1,599-11,297; $\mathrm{P}=0.004)$; thus, they stated that the genetic factor may contribute to the etiology of sleep bruxism. Particularly stress and anxiety of symptoms were assessed via a short dichotomous question-type questionnaire, making it difficult to establish the level of stress and/or anxiety and its difference with the control group. In the present study, with the results of the psychometric instruments used at hand, the presence of anxiety and neuroticism traits in individuals with bruxism was confirmed.

In order to perform genotype analysis, the sample was divided by generations and four groups were established according to self-reported signs and symptoms. The Hardy-Weinberg test was used in this sample; however, when performing the analysis of genotypic homogeneity (genotypes $\mathrm{C} / \mathrm{C}, \mathrm{C} / \mathrm{T}$ and $\mathrm{T} / \mathrm{T})$ vs. the four groups, $(3 \times 4)$, no trend was observed between the SNP rs6313 and the individuals from the different analyzed groups $(\mathrm{F}=4.517, \mathrm{P}=0.612)$. In contrast to the subjects from Japan, in this population from northeastern Mexico, there was no significant genetic association found, which is explained by the close relationship between genetic factors and the environment and by its influence to cause individual differences in genes related to personality traits, cognitive skills, and specifically, bruxism $(31,32)$. However, out of the four groups, the farthest from significance was the control group with $\mathrm{P}=0.82$, unlike the combined bruxism group with $\mathrm{P}=0.10$. For this reason, the latter group was considered for odds ratio analysis, determining that combined bruxism has a higher relative risk of neuroticism traits (OR=15.0; CI 1.52-148.32), and a higher relative risk of anxiety symptoms in grade 3 -moderate (OR=3.56; 1.27-10.03), and in grade 4-severe (OR=8.40; CI 1.45-48.61). In this study, through the use of psychometric scales, a positive correlation between anxiety and neuroticism psychological traits in subjects with self-reported symptoms of bruxism, can be confirmed, additionally noting that the highest score was reported by subjects who self-reported combined bruxism. Thus, the association between greater perception of symptoms of bruxism with sensitivity to symptoms of anxiety and neuroticism trait is strengthened. Furthermore, these data were confirmed by separating the sample by generations and by genotypic homogeneity. This evaluation found that combined bruxism has a higher relative risk of developing traits of neuroticism and anxiety symptoms in grade 3 -moderate and grade 4 -severe individuals. No significant difference was found in the association between patients with bruxism (sleep, 
waking or combined) and the rs6313 polymorphism $H T R 2 A$ gene. Polymorphisms associated with either normal or pathological traits are population-related; thus, it may be that either this is not related to bruxism in our population or it may be due to the heterogeneity of the Mexican population as well as the size of the sample.

\section{Acknowledgements}

Corresponding author thanks the CONACYT for its support of the scholarship (337518/285502).

\section{References}

1. Lobbezoo F, Ahlberg J, Glaros AG, Kato T, Koyano K, Lavigne GJ, de Leeuw R, Manfredini D, Svensson P and Winocur E: Bruxism defined and graded: An international consensus. J Oral Rehabil 40: 2-4, 2013.

2. Ahlberg J, Lobbezoo F, Ahlberg K, Manfredini D, Hublin C, Sinisalo J, Könönen M and Savolainen A: Self-reported bruxism mirrors anxiety and stress in adults. Med Oral Patol Oral Cir Bucal 18: e7-e11, 2013.

3. Manfredini D, Winocur E, Guarda-Nardini L, Paesani D and Lobbezoo F: Epidemiology of bruxism in adults: A systematic review of the literature. J Orofac Pain 27: 99-110, 2013.

4. Machado E, Dal-Fabbro C, Cunali PA and Kaizer OB: Prevalence of sleep bruxism in children: A systematic review. Dental Press J Orthod 19: 54-61, 2014.

5. Castroflorio T, Bargellini A, Rossini G, Cugliari G, Rainoldi A and Deregibus A: Risk factors related to sleep bruxism in children: A systematic literature review. Arch Oral Biol 60 : 1618-1624, 2015.

6. Paesani DA (ed): Bruxism: Theory and practice. 1st edition. Quintessence Publishing, New Malden, UK, pp3-5, 2010.

7. Lobbezoo F, Ahlberg J, Manfredini D and Winocur E: Are bruxism and the bite causally related? J Oral Rehabil 39: 489-501, 2012.

8. Bayar GR, Tutuncu R and Acikel C: Psychopathological profile of patients with different forms of bruxism. Clin Oral Investig 16: 305-311, 2012.

9. Lobbezoo F, Visscher CM, Ahlberg J and Manfredini D: Bruxism and genetics: A review of the literature. J Oral Rehabil 41: 709-714, 2014

10. Michalowicz BS, Pihlstrom BL, Hodges JS and Bouchard TJ Jr: No heritability of temporomandibular joint signs and symptoms. J Dent Res 79: 1573-1578, 2000

11. Abe Y, Suganuma T, Ishii M, Yamamoto G, Gunji T, Clark GT, Tachikawa T, Kiuchi Y, Igarashi Y and Baba K: Association of genetic, psychological and behavioral factors with sleep bruxism in a Japanese population. J Sleep Res 21: 289-296, 2012.

12. Muguruza C, Moreno L, Umali A, Callado L, Meana J and González J: Dysregulated 5-HT2A receptor binding in postmortem frontal cortex of schizophrenic subjects. Eur Neuropsychopharmacol 23: 852-864, 2013.

13. Kishi T, Yoshimura R, Kitajima T, Okochi T, Okumura T, Tsunoka T, Yamanouchi Y, Kinoshita Y, Kawashima K, Naitoh H, et al: HTR2A is associated with SSRI response in major depressive disorder in a Japanese cohort. Neuromolecular Med 12: 237-242, 2010.

14. Holliday KL, Macfarlane GJ, Nicholl BI, Creed F, Thomson W and McBeth J: Genetic variation in neuroendocrine genes associates with somatic symptoms in the general population: Results from the EPIFUND study. J Psychosom Res 68: 469-474, 2010.
15. Wilhelm K, Siegel JE, Finch AW, Hadzi-Pavlovic D, Mitchell PB, Parker G and Schofield PR: The long and the short of it: Associations between 5-HTT genotypes and coping with stress. Psychosom Med 69: 614-620, 2007.

16. Kiser D, Steemers B, Branchi I and Homberg JR: The reciprocal interaction between serotonin and social behaviour. Neurosci Biobehav Rev 36: 786-798, 2012.

17. Donnellan MB, Burt SA, Levendosky AA and Klump KL: Genes, personality, and attachment in adults: A multivariate behavioral genetic analysis. Pers Soc Psychol Bull 34: 3-16, 2008.

18. Fraley RC, Roisman GI, Booth-LaForce C, Owen MT and Holland AS: Interpersonal and genetic origins of adult attachment styles: A longitudinal study from infancy to early adulthood. J Pers Soc Psychol 104: 817-838, 2013.

19. Secretaría de Salud: Subsecretaría de Prevención y Promoción de la Salud. Manual de procedimientos estandarizados para la vigilancia epidemiológica de las patologías bucales, 2012. http://www.cenaprece.salud.gob.mx/programas/interior/saludbucal/descargas/pdf/20_2012_Manual_PatBucales_vFinal.pdf

20. Huang H, Song YH, Wang JJ, Guo Q and Liu WC: Excitability of the central masticatory pathways in patients with sleep bruxism. Neurosci Lett 558: 82-86, 2014.

21. Klasser GD, Greene CS and Lavigne GJ: Oral appliances and the management of sleep bruxism in adults: A century of clinical applications and search for mechanisms. Int J Prosthodont 23: 453-462, 2010.

22. Schneider C, Schaefer R, Ommerborn MA, Giraki M, Goertz A, Raab WH and Franz M: Maladaptive coping strategies in patients with bruxism compared to non-bruxing controls. Int J Behav Med 14: 257-261, 2007.

23. Gungormus Z and Erciyas K: Evaluation of the relationship between anxiety and depression and bruxism. J Int Med Res 37: 547-550, 2009

24. Esquerra-Trabalon M, Gallardo-Pujol D and Robles-Muñoz N: Metodología y técnicas en genética del comportamiento. In: Bases Genéticas de la Conducta. Bartrés D and Redolar D (eds). Editorial UOC, Barcelona, pp19-90, 2014.

25. Dworkin SF and LeResche L: Research diagnostic criteria for temporomandibular disorders: Review, criteria, examinations and specifications, critique. J Craniomandib Disord 6: 301-355, 1992.

26. Cruz N, González M and Vanegas M: Validation of the self-reported bruxism questionnaire. (unpublished data).

27. Robles R, Varela R, Jurado S and Páez F: Versión mexicana del inventario de ansiedad de Beck: Propiedades psicométricas. Rev Mex Psicol 18: 211-218, 2001.

28. Sandin B, Valiente R, Chorot P, Olmedo M and Santed M: Versión española del cuestionario EPQR-Abreviado (EPQR-A) (I): Análisis exploratorio de la estructura factorial. Rev Psicopatol Psicol Clin 7: 195-205, 2002 (In Spanish).

29. Applied Biosystems: TaqMan ${ }^{\circledR}$ Gene expression Assays Protocol, 2010. https://tools.thermofisher.com/content/sfs/ manuals/cms 041280.pdf.

30. Rintakoski K, Hublin C, Lobbezoo F, Rose RJ and Kaprio J: Genetic factors account for half of the phenotypic variance in liability to sleep-related bruxism in young adults: A nationwide Finnish twin cohort study. Twin Res Hum Genet 15: 714-719, 2012.

31. Johnson W and Vernon T: Introduction to a special issue on behavioral genetics. Pers Individ Dif 53: 366-367, 2012.

32. Luciano M, MacLeod A, Payton A, Davies G, Ke X, Tenesa A, Ollier W, Starr J, Horan I, Pendleton N, et al: Effects of gene copy number variants on personality and mood in ageing cohorts. Pers Individ Dif 53: 393-397, 2012. 